between 1980 and 2007, the president and the congressional majority have come from different parties. We may feel more polarized today because, especially through the media, we are in daily contact with those with whom we disagree.

Nor should terrorism be thought of as simply the product of group polarization. Terrorism has long been an effective tactic for non-state actors with political goals, and is supported and funded by large sections of the societies in which they live.

Going to Extremes is a fine book full of insightful evidence and intelligent commentary on modern political life. Sunstein's vision of emancipatory political discourse is salutary, and the world would probably be a better place if we followed it. But this is only one aspect of how we form beliefs.

Herbert Gintis is professor of economics at the Central European University, 1051 Budapest, Hungary, and external professor at the Santa Fe Institute, Santa Fe, New Mexico 87501, USA. e-mail:hgintis@comcast.net

\title{
Society need not be selfish
}

\author{
The Age of Empathy: Nature's Lessons \\ for a Kinder Society \\ by Frans de Waal \\ Random House: 2009. 320 pp. $\$ 25.99$
}

In the 1950s and 1960s, a major topic of research in animal behaviour was aggression. Konrad Lorenz's popular 1966 book, On Aggression, argued that it has an important role in the social life of many animal species, including humans. The idea struck a chord with the public - perhaps because the memory of the Second World War was still fresh and the emerging cold war showed that even allies could turn on one another. Lorenz also noted that many animal species had "aggression-inhibiting mechanisms" to keep things from getting out of hand. But he thought that humans were especially underequipped with these.

In the late 1970s, ethologist Frans de Waal began to study the aggression-inhibiting mechanisms of various primate species, which led to the discovery that primates often reconcile

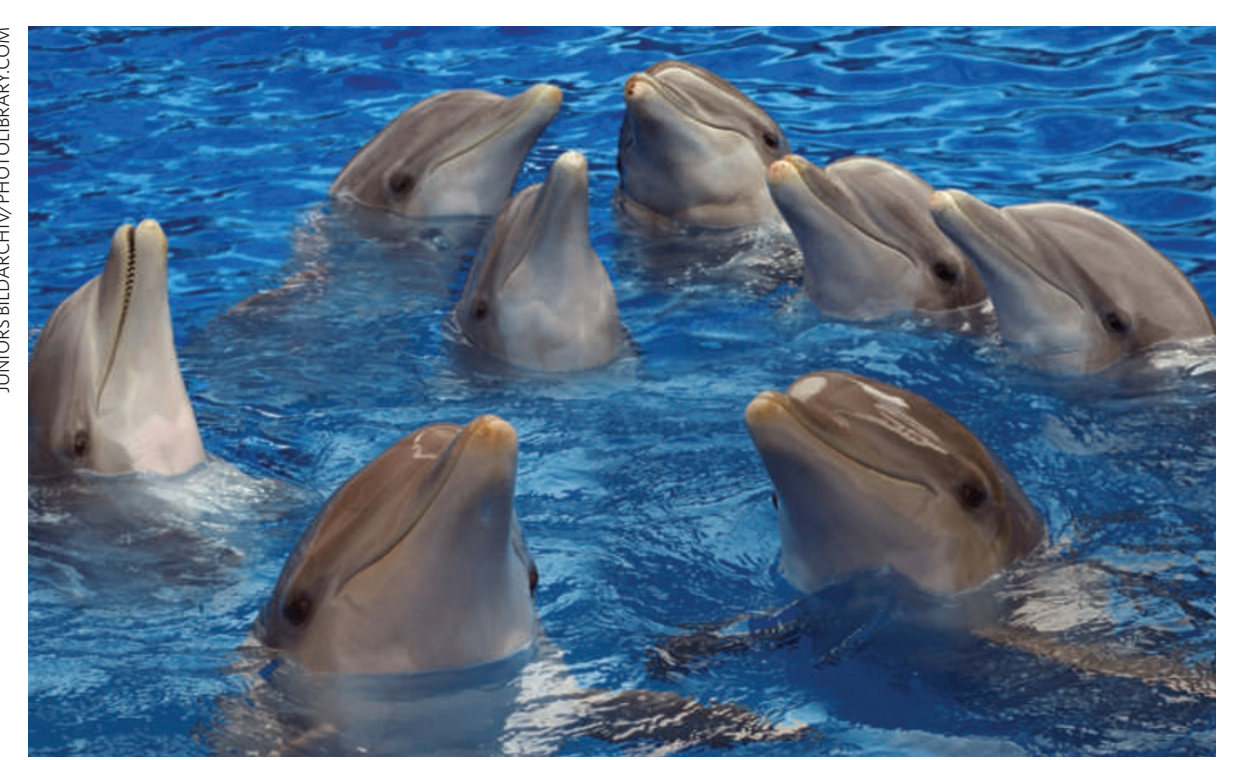

Dolphins' ability to cooperate, argues Frans de Waal, is evidence that evolution favours altruism.

after fighting. Combatants will seek out one another and display some kind of peacemaking behaviour that often involves touching, as de Waal summarizes in his 1989 book Peacemaking Among Primates (Harvard University Press). The phenomenon has turned out to be robust and widespread, even among some nonprimate mammals. De Waal has also studied reciprocity in primates: food sharing, support in fights and grooming seem to be exchanged in kind in many species.

Over the past 15 years or so, de Waal has written a series of popular books with the main theme that humans are more similar to other animals in their attitudes and behaviour than most people realize. In particular, he has set out to combat the idea that evolution selects exclusively for individualistically selfish behaviour in animals. He argues that evolution has also selected for conciliation, cooperation and even empathy in many species, most obviously in those who live in complex social groups, which includes most mammals and almost all primates. To the chagrin of many scientists, de Waal's books often weave together seamlessly systematic research with informal anecdotes of animal behaviour.

In his latest volume, The Age of Empathy, de Waal continues these same themes but with more focus on the implications for how we should conduct ourselves and construct our societies. His evidence is drawn from nonhuman primates, dolphins, elephants and various domesticated animals, including his own pet cat. He also scrutinizes some politicians and popular figures from the point of view of animal behaviour. A repeated foil throughout is Gordon Gekko, from the 1987 movie Wall Street, who reiterates in various forms the basic credo that "greed is good".

As a European living in the United States, de Waal compares a cooperative, collectivist and caring society with one that is more focused on individuals' rights and responsibilities - confessing his own sentiments to lie "somewhere in the middle of the Atlantic". His main political message is that we should not continue to harp on about evolution justifying only the selfish side of human nature, although of course that exists. He urges that we must also capitalize on the empathetic and cooperative attitudes that evolution has equipped us with, writing: "A society that ignores these tendencies can't be optimal".

De Waal's latest book does not address fundamental questions about the evolution of cooperation, empathy or altruism, nor how humans evolved exaggerated forms of these to become fully moral agents. But for those who still equate the terms 'beastly' and 'apelike' with fundamentally selfish and aggressive behaviour, and who believe that evolution is always "red in tooth and claw", The Age of Empathy is an excellent antidote. Whether this book, or indeed any study of the natural world, also provides concrete lessons for human society is another question.

Michael Tomasello is professor of developmental and comparative psychology at the Max Planck Institute for Evolutionary Anthropology, D-04103 Leipzig, Germany. His forthcoming book is Why We Cooperate. 